\title{
Rheological, Baking and Sensory Characteristics of Bread from Wheat-Cassava Composite Dough
}

\author{
John Manano ${ }^{1}$, Patrick Ogwok ${ }^{1}$, George William Byarugaba-Bazirake ${ }^{1} \&$ Ediriisa Mugampoza $^{1}$ \\ ${ }^{1}$ Department of Food Technology, Kyambogo University, Kyambogo, Uganda \\ Correspondence: John Manano, Department of Food Technology, Kyambogo University, P.O.Box 1, Kyambogo, \\ Uganda. E-mail: jmanano@yahoo.com
}

Received: August 12, 2021

doi:10.5539/jfr.v10n5p18
Accepted: September 11, $2021 \quad$ Online Published: September 16, 2021

URL: https://doi.org/10.5539/jfr.v10n5p18

\begin{abstract}
Uganda produces cassava, which has potential as a raw material for agro-industry. In this study, wheat flour was blended with high quality cassava flour in the ratios 100:0, 90:10; 80:20; 70:30; 60:40; 50:50 and 40:60 and the composite dough used to prepare bread. The doughs were subjected to rheological analysis using mixolab, consistograph and alveograph. Bread physical properties were measured and sensory qualities evaluated to correlate rheological characteristics of flour/dough with bread quality. Inclusion of cassava flour in the composite dough negatively affected the quality of the composite bread compared to the control. Bread volume $\left(631.0\right.$ to $\left.516.7 \mathrm{~cm}^{3}\right)$ decreased, specific volume $\left(2.065\right.$ to $\left.1.574 \mathrm{~cm}^{3} / \mathrm{g}\right)$ decreased, bread density $(0.49$ to 0.63 $\left.\mathrm{g} / \mathrm{cm}^{3}\right)$ increased. Mean scores for sensory quality parameters reduced: crust colour (6.88 to 4.63$)$, taste (7.13 to $4.25)$, crumb texture (6.5 to 4.63 ) and overall acceptability ( 8.13 to 4.5$)$. Bread quality was positively correlated with mixolab parameters protein weakening (C2), dough stability and dough development time (DDT); alveograph parameters tenacity $(\mathrm{P})$ and deformation energy $(\mathrm{W})$; and consistograph parameter maximum pressure (PrMax). Results showed that bread of acceptable quality can be processed using wheat composite containing $20 \%$ cassava flour. Rheological properties can be used to assess suitability of flour for bread making.
\end{abstract}

Keywords: rheology, mixolab, alveograph, consistograph, composite flour/dough, bread

\section{Introduction}

Uganda's population is increasing at a rate of $3.32 \%$ per annum and the youth ( $18-30$ years) is about $34.8 \%$ of the total population of 46.8 million (UNFPA, 2016; UBOS, 2020). Consumption of wheat-based products is expected to increase as population and urbanization increases and new food habits are adopted by the youth. The youth develop new food habits, mostly feeding on wheat-based convenient foods including chapattis, mandazi, doughnuts, baghias, bread, confectioneries and pasta. Uganda's demand for wheat, estimated at 500000 MT per year, is higher than its domestic supply of 20000 MT (USDA, 2018). This makes the country a net importer of wheat, which takes a big chunk of the country's foreign exchange reserves, hence making bread a luxury commodity for most communities. Partial substitution of wheat flour with cassava flour, a local raw material, in the manufacture of bakery and confectionery products is thus economically important in Uganda. Wheat is inevitable in bread making because it contains glutenin and gliadin, the proteins responsible for the dough-forming capacity of wheat flour, by forming gluten on hydration (Kent and Evers, 1994; Anjum et al., 2007). The gluten binds flour particles together in dough, traps air bubbles incorporated into the dough during mixing and allows the expansion of the dough when carbon dioxide produced during dough fermentation mixes with the air bubbles, thus forming foam.

Cassava is the second most important food crop, after plantain, in Uganda, with an estimated production of 2, 841, 625 tonnes in 2019 (FAOSTAT, 2021). Currently, utilization of cassava is limited to semi-processed products such as dried chips and cassava flour through the informal sector. Cassava is therefore, not fully utilized in Uganda. The crop has great technological potential as a raw material for agro-industrial products, primarily as dried chips or high quality cassava flour (HQCF) for baked products, confectioneries and breweries (C:AVA, 2018). The biscuit industry could replace up to $35 \%$ of wheat flour with HQCF (Kleih et al., 2012). The challenges to the use of HQCF in manufacturing processes is the failure by suppliers to supply commercial quantities of the correct quality at the correct time, and lack of national policy with regard to the inclusion of HQCF in wheat-based products. HQCF has a market opportunity, as a local food product and as a potential 
replacement for wheat, both of which have not been fully exploited (C: AVA, 2018). High quality cassava flour is white/cream, odourless and has a bland neutral taste and can thus easily blend with wheat flour.

High quality cassava flour has low sodium content, causes no allergic effects when consumed by patients with celiac disease and contains easily-digested carbohydrates (Bayata, 2019; Lu et al., 2019). The starch composition, lower retrogradation tendency, melting onset, and water absorption of cassava flour are similar to those of wheat flour (Lu et al., 2019). Cassava flour, however, contains little protein, 1 - 2\% (Dendy, 1992; Manano et al., 2017), and no gluten-forming proteins. When the flour is mixed with wheat flour, it acts as a diluent to gluten, and impairs the quality of the baked products made from the composite flour. In order to obtain high quality attributes for baked products, researchers have embarked on the determination of rheological qualities of flour and the corresponding dough, e.g. farinograph, extensograph, and amylograph (Xhabiri et al., 2016; Jensen et al., 2015). Investigations into the incorporation of HQCF into wheat flour for bread making have mainly concentrated on the overall acceptability of the composite bread to consumers (Agunbiade et al., 2017; Abass et al., 2018; Sampson, 2020) and the toxicity of the product (Owuamanam, 2007; Eleazu et al., 2014; Iwe et al., 2017). Few studies have focused on the rheological characteristics of wheat-cassava composite flours in relation with the quality of the corresponding finished products (bread, chapatti, pasta) (Jensen et al., 2015; Olubunmi et al., 2015). In this study the mixolab, alveograph and consistograph were used to determine the rheological properties of the wheat-cassava composite flours, which were used to make bread.

\section{Methodology}

\subsection{Sample Collection and Preparation}

Freshly harvested cassava roots from the Namulonge Selection (NASE 14) were purchased from a farmer at Pukweru village, Panyango sub-county in Nebbi district, Uganda. The roots were taken to Food Technology Laboratory at Kyambogo University for preliminary processing.

Wheat flour (AZAM brand, home baking flour, Bakhresa Grain Milling, (U) Ltd.), sugar, shortening, salt, nutmeg and instant yeast ( 2 in1, Plus brand, Fabrique en France par, France) were purchased from local food stores in Kampala.

\subsubsection{Production of High Quality Cassava Flour}

Cassava roots were processed into high quality flour using the modified method described by IITA (2006). Freshly harvested cassava roots were peeled and washed in clean portable running water. The peeled roots were sliced using a grating hand-machine into smaller pieces, approximately 1 to $2 \mathrm{~mm}$ thick, dried at $50{ }^{\circ} \mathrm{C}$ for $24 \mathrm{hrs}$ in a hot- air oven (Carbolite, 4EKF63A - 251, Greiffer berger ABM, Korea) and cooled to ambient temperatures $\left(18\right.$ to $22{ }^{\circ} \mathrm{C}$ ) for $3 \mathrm{hrs}$. The dried cassava chips were packaged in dry, new, high density polyethylene bags (HDPE), and stored at ambient temperature prior to analysis and utilization. Before analysis, the dried cassava chips were ground to powder using Sunbeam grinder (model SCG-2012, NU WORLD IND, PTY Ltd., Southern Africa).

The analyses were carried out at Uganda Industrial Research Institute (UIRI) and Kyambogo University Business Incubation Centre (BIC).

\subsection{Determination of Moisture}

The moisture content of cassava and wheat flour was measured by weight difference before and after drying of the samples in a hot-air oven as described by AOAC (1995). Two crucibles were washed and dried in a hot-air oven at $105^{\circ} \mathrm{C}$ to a constant weight. The crucibles were cooled in a desiccator for $30 \mathrm{~min}$, labeled and weighed $\left(\mathrm{W}_{1}\right)$. Each sample was weighed $(2.0 \mathrm{~g})$ into crucibles and reweighed $\left(\mathrm{W}_{2}\right)$. The crucibles containing the samples were placed in an oven maintained at $105^{\circ} \mathrm{C}$ until constant weight was observed. They were transferred to a desiccator to cool and finally weighed $\left(\mathrm{W}_{3}\right)$. Moisture content was calculated as the difference between weights $\mathrm{W}_{3}$ and $\mathrm{W}_{2}$, and expressed as a percentage.

\subsection{Determination of the $\mathrm{pH}$ of Flour}

Ten grams of flour was weighed into a $250 \mathrm{ml}$ beaker. Distilled water $(90 \mathrm{ml})$ was added and the content mixed homogeneously, and then left for $1 \mathrm{hr}$ at room temperature. The $\mathrm{pH}$ was measured using a $\mathrm{pH}$ meter (Mettler Toledo, Switzerland). The $\mathrm{pH}$ meter was first calibrated with buffers of $\mathrm{pH} \mathrm{4,} \mathrm{pH} 7$, and $\mathrm{pH} 10 . \mathrm{pH}$ values were measured in triplicate, meanwhile, the meter was washed thoroughly using distilled water after each measurement.

\subsection{Determination of Total Titratable Acidity of the Flour}

Titratable acidity (TA) was determined using AACC (2000) method, where $25 \mathrm{ml}$ of the filtrate obtained from 5 
$\mathrm{g}$ of HQCF sample dissolved in $50 \mathrm{ml}$ of distilled water was collected in a $100 \mathrm{ml}$ flask. Three drops of $1 \%$ phenolphthalein indicator were added to the solution in the flask and thoroughly mixed. Titration was carried out by adding $0.1 \mathrm{M} \mathrm{NaOH}$ until end point identified by a colour change to pink which persisted for about $30 \mathrm{~s}$. The volume of $\mathrm{NaOH}$ added was multiplied by 0.09 to obtain the \% titratable acidity as lactic acid $(1 \mathrm{~mL}$ of $0.1 \mathrm{M}$ $\mathrm{NaOH}=0.009 \mathrm{~g}$ of lactic acid).

\subsection{Formulation of Wheat-cassava Composite Flour}

Wheat and cassava flour composites were formulated in the ratios: 100:0, 90:10, 80:20, 70:30, 60:40, 50:50, and 40:60 respectively and stored in high density polyethylene bags (HDPE) prior to utilisation and analysis.

\subsection{Rheological Characterisation of the Composite Flour}

\subsubsection{Mixolab Properties}

Mixolab analysis was carried out using the water absorption level determined by the consistograph according to the method of AACC 54-30 (2000). The standard "Chopin +" protocol was followed: initial equilibrium at $30{ }^{\circ} \mathrm{C}$ for $8 \mathrm{~min}$, heating to $90{ }^{\circ} \mathrm{C}$ over $15 \mathrm{~min}$ (at a rate of $4{ }^{\circ} \mathrm{C} / \mathrm{min}$ ), holding at $90{ }^{\circ} \mathrm{C}$ for $7 \mathrm{~min}$, cooling to $50^{\circ} \mathrm{C}$ over 5 min (at a rate of $4{ }^{\circ} \mathrm{C} / \mathrm{min}$ ), and holding at $50{ }^{\circ} \mathrm{C}$ for $5 \mathrm{~min}$. The mixing speed was kept constant at $80 \mathrm{rpm}$. The parameters recorded were: water absorption (the percentage of water required for the dough to produce a torque of $1.1 \pm 0.05 \mathrm{Nm}$ ), dough development time, min (the time to reach the maximum torque at $30{ }^{\circ} \mathrm{C}$ ), dough stability at mixing, min (the elapsed time at which the torque produced is kept at $1.1 \mathrm{Nm}$ ), $\mathrm{C} 1$ (determines absorption/dough development),

$\mathrm{C} 2$ (measures the weakening of the protein/decrease in dough consistency based on the mechanical work and the temperature), C3 (measures starch gelatinization, i.e. starch granules swell and absorb water and amylase molecules leach out resulting in an increase in the viscosity), $\mathrm{C} 4$ (measures the stability of the hot-formed gel/amylase activity), C5 (measures starch retrogradation/gelling during the cooling period) (Mixolab Applications Handbook, Chopin Technologies, 2012). The standard plots/curve (Figure 1) was converted into 6 indices rated from 0 to 9 , which profiled flour on the basis of 6 fundamental criteria: absorption potential or water absorption index, mixing properties or mixing index, gluten strength or gluten+ index, maximum viscosity or viscosity index, amylase activity or amylolysis/amylase index and retrogradation index. Other parameters represent rates at which the process was taking place: $\alpha$ - represents the slope of the curve between the end of the period at $30{ }^{\circ} \mathrm{C}$ and $\mathrm{C} 2$ gives an indication about protein weakening speed under the effect of heat; $\beta$ represents the slope of the curve between $\mathrm{C} 2$ and $\mathrm{C} 3$, and gives an indication about starch gelatinization speed; $\gamma$ - represents the slope of the curve between $\mathrm{C} 3$ and $\mathrm{C} 4$, and gives an indication about enzyme biodegradation speed. An average of three independent determinations was recorded.

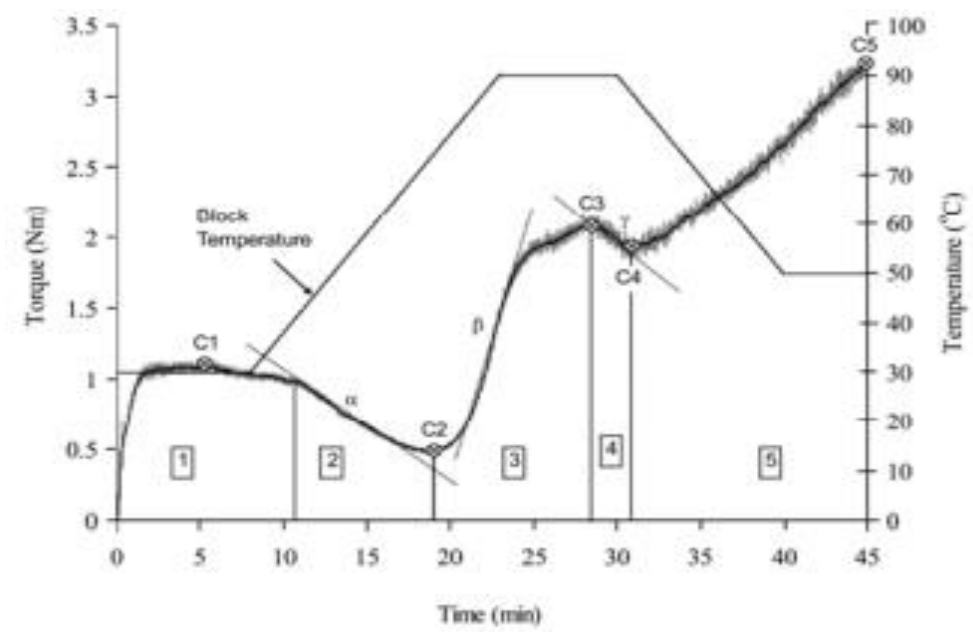

Figure 1. A standard mixolab curve (Mixolab Applications Handbook, 2012)

\subsubsection{Consistograph Properties}

The effect of cassava flour substitution on the rheological characteristics of wheat flour was studied using consistograph (AlveoLAB, Chopin Technologies, Villeneuve-la-Garenne, France), according to AACC (2000) method. Consistographic characteristics determined were: water absorption capacity (WAC) and maximum 
pressure (PrMax). An average of three independent determinations was recorded.

\subsubsection{Alveograph Properties}

Alveograph test was carried out according to AACC (2000) method using alveograph (AlveoLAB, Chopin Technologies, Villeneuve-la-Garenne, France). Alveograph parameters automatically recorded by a computer software were: maximum overpressure $(\mathrm{P})$ needed to blow the dough bubble, an index of resistance to extension (elasticity); the average abscissa (L) at bubble rupture, an index of dough extensibility; the ratio of the tenacity to the extensibility of the dough, P/L; the deformation energy (W), an index of dough strength; and flexibility index, Ie.

\subsection{Baking of the Composite Bread}

A modification of the recipe for bread production proposed by Sanni et al. (2006) was used to formulate the bread loaves in this study. The amount of water used was determined by the Mixolab, and not the $100 \mathrm{ml}$ proposed in the recipe. The straight dough method was used. Bread was prepared with the following ingredients: flour (200 g), water (100 ml), margarine (45 g), sugar (25 g), salt (1.5 g), dried instant yeast $(2.5 \mathrm{~g})$ and nutmeg $(0.5 \mathrm{~g})$. Bread baked with $100 \%$ wheat flour was used as control. Mixing was done manually for 15 min prior to kneading. The dough was kneaded manually for 3 to 5 min until smooth dough of uniform consistency was obtained. The dough was moulded into loaves, transferred immediately into greased baking pans, and proofed for $30 \mathrm{~min}$ at room temperature. The loaves were baked in an electric oven (Gallenkamp, London, UK) at $200 \pm$ $2{ }^{\circ} \mathrm{C}$ for $30 \mathrm{~min}$, removed after baking, cooled to ambient temperature and wrapped in polyethylene bags ready for analysis.

\subsubsection{Determination of Loaf Weight}

Loaf weight was determined using the method of AACC (2000). Loaf weight was determined after sufficient (2 hrs) cooling using a digital weighing scale, RADWAG (0.001 g accuracy) (RADWAG Wagl Elektroniczne, WTC 3000 , Poland). Independent measurements were recorded in triplicates.

\subsubsection{Determination of Bread Volume and Density}

The weight (W) of the loaf was measured. Loaf volume (VL) was determined by the Rapeseed Displacement Method according to the AACC (2000) as modified by Greene and Bovell-Benjamin (2004). Millet seeds were used instead of rapeseeds.

The loaf was put in a baking can of known volume (VB) and the baking can filled to the brim with millet seeds. The edge of a meter rule was used to cut off all seeds above the can rim such that the seeds formed a plateau with the rim of the can. The loaf was removed and the volume of the millet seeds (VM) was measured with a measuring cylinder. Loaf volume (VL) was then determined according to the following formula:

$$
\mathrm{VL}\left(\mathrm{cm}^{3}\right)=\mathrm{VB}-\mathrm{VM}
$$

Specific volume (SV) was calculated using the equation: $\mathrm{SV}\left(\mathrm{cm}^{3} / g\right)=\mathrm{VL} / \mathrm{W}$

while density was calculated using the equation: DL $\left(\mathrm{g} / \mathrm{cm}^{3}\right)=\mathrm{W} / \mathrm{VL}$

\subsubsection{Determination of Water Loss in Bread}

The weight of the bread loaf was measured 2 hrs after baking. Water loss was calculated as the difference between the total weight of raw materials and the weight after baking and expressed as a percentage.

Water Loss $=$ ingredients total weight - loaf final weight

\subsubsection{Sensory Evaluation}

Bread loaves were allowed to cool for $12 \mathrm{hrs}$ and cut into slices of uniform thickness and transferred onto white-coloured plates coded with random 3-digit codes. A sensory panel consisting of 20 randomly selected semi-trained staff members and graduate students at Kyambogo University, who are familiar with the sensory attributes of local bread, was employed to evaluate the products. A 9-point Hedonic scale was used to rate the breads for crust colour, taste, crumb texture and overall acceptability. A score of 1 represented "dislike extremely", 5 - neither like nor dislike, and 9 represented "like extremely" (Lawless and Heymann, 2010). An atmosphere of complete quietness, conventional lighting and privacy was provided for each panelist. Seven bread samples were evaluated simultaneously and served randomly and individually to the panelists along with water to cleanse/rinse their palate between tasting. Each panelist was served separately with a loaf of bread for external quality assessment and a slice of about $3 \mathrm{~cm}$ thick from the same sample for crumb assessment. 


\section{Statistical data Analysis}

Quantitative data were subjected to analysis using the IBM Statistical Package for Social Sciences (SPSS), version 23. Results were presented as Means \pm standard deviations. One-way analysis of variance (ANOVA) was used to test for the difference among the composite flours. Differences between means were considered significant at $\mathrm{p}<0.05$.

The Mixolab Profiler indices were systematically rounded to the nearest unit. A difference of 1 point on the Profiler was regarded not a significant difference (Mixolab Applications Handbook, Chopin Technologies, 2012).

The relationship between proportion of cassava addition (\%), dough rheology and bread physical and sensory properties was evaluated by principal component analysis (PCA) using XLSTAT (v.2.2, 2019).

\section{Results and Discussion}

\subsection{Physico-chemical and Functional Characteristics of Flour}

The cassava flour had a pH of $6.22 \pm 0.01$ (Table 1). The $\mathrm{pH}$ of the high quality cassava flour was acceptable according to the quality requirements (East African Standard, DEAS 779:2012). The pH is a good quality indicator for cassava flour since flour with a $\mathrm{pH}$ of 4 or less indicates significant degree of fermentation, and thus some starch breakdown, which imparts characteristic sour aroma and taste, making the flour undesirable for use in bakery products (Apea-Bah et al., 2011). Any decrease in $\mathrm{pH}$ from near neutral (pH 7) and increase in titratable acidity (above about $2 \%$ ) is a result of fermentation. $\mathrm{pH}$ is a critical factor in developing flavour and aroma characteristics of foods (Tetchi et al., 2012). pH is active acidity of the food, in this case of cassava flour and thus, the lower the $\mathrm{pH}$, the sour the flour. Lactic acid bacteria have been reported to be implicated throughout the duration of fermentation of cassava into fermented products, their activity imparts the typical sour fermented taste to these products (Oyewole and Odunfa, 1988).

Table 1. Physico-chemical properties of cassava flour and wheat flour

\begin{tabular}{lll}
\hline & Flour type \\
\hline Properties & Cassava & Wheat \\
\hline Moisture content, $\%$ & $12.46 \pm 0.23$ & $13.58 \pm 0.18$ \\
pH & $6.22 \pm 0.01$ & $6.01 \pm 0.03$ \\
Total titratable acidity $\%$ & $0.038 \pm 0.00$ & $0.031 \pm 0.00$ \\
\hline
\end{tabular}

The values are means $\pm \mathrm{SD}$ of independent triplicate determinations

The cassava flour in this study had a total titratable acidity of $0.038 \pm 0.00 \%$ (Table 1). This was within the acceptable limit of $<0.25 \%$ according to the quality requirements (East African Standard, DEAS 779:2012). Total titratable acidity (TTA) is a better indicator of fermentation activity than $\mathrm{pH}$ because it continues to increase after $\mathrm{pH}$ (active acidity) levels off. An increase in titratable acidity (above about $2 \%$ ) is a result of fermentation. The level of acidification increases with increasing period of fermentation (Oyewole and Ogundele, 2001). The lowering of $\mathrm{pH}$ and the concomitant increase in titratable acidity is attributed to accumulation of organic acids such as lactic and acetic acids in the fermenting cassava produced by activities of bacteria (Bacillus sp., Leuconostoc sp., Klebsiella sp., Corynebacterium sp., Lactobacillus sp) and yeasts (Candida sp., Aspergillus sp., and Geotrichum sp) which contribute the dominant specific microflora (Oyewole and Odunfa, 1988).

The HQCF had a moisture content of $12.46 \pm 0.07 \%$ while wheat flour had a moisture content of $13.58 \pm 0.19 \%$ (Table 1). The moisture content of the flour should be known in order to configure the mixolab equipment before the determination of rheological properties of the flour/dough. In this study, analysis was performed on 14 moisture content basis (Mixolab Applications Handbook, 2012).

\subsection{Mixolab Indices of Wheat-cassava Composite Flour}

Mixolab index for water absorption ranged from 3 to 9; mixing index ranged from 1 to 5; Gluten+ index ranged from 3 to 7 ; viscosity index ranged from 1 to 8 ; amylase index ranged from 2 to 8 and retrogradation index ranged from 4 to 8 (Table 2). 
Table 2. Mixolab indices of wheat-cassava composite flour (14 moisture content basis)

\begin{tabular}{lllllllll}
\hline \multicolumn{2}{l}{ Proportion of cassava in composite flour, \% } \\
\hline Mixolab indices & $0 \% \mathrm{CF}$ & $10 \% \mathrm{CF}$ & $20 \% \mathrm{CF}$ & $30 \% \mathrm{CF}$ & $40 \% \mathrm{CF}$ & $50 \% \mathrm{CF}$ & $60 \% \mathrm{CF}$ & $100 \% \mathrm{CF}$ \\
\hline Water absorption & $4^{\mathrm{a}}$ & $4^{\mathrm{a}}$ & $3^{\mathrm{ab}}$ & $5^{\mathrm{a}}$ & $7^{\mathrm{c}}$ & $8^{\mathrm{cd}}$ & $8^{\mathrm{cd}}$ & $9^{\mathrm{d}}$ \\
Mixing & $4^{\mathrm{ab}}$ & $4^{\mathrm{ab}}$ & $5^{\mathrm{a}}$ & $3^{\mathrm{b}}$ & $1^{\mathrm{c}}$ & $1^{\mathrm{c}}$ & $1^{\mathrm{c}}$ & $3^{\mathrm{b}}$ \\
Gluten+ & $4^{\mathrm{a}}$ & $4^{\mathrm{a}}$ & $4^{\mathrm{a}}$ & $3^{\mathrm{ac}}$ & $3^{\mathrm{ac}}$ & $4^{\mathrm{a}}$ & $5^{\mathrm{ab}}$ & $7^{\mathrm{d}}$ \\
Viscosity & $8^{\mathrm{a}}$ & $8^{\mathrm{a}}$ & $8^{\mathrm{a}}$ & $7^{\mathrm{ab}}$ & $6^{\mathrm{bc}}$ & $5^{\mathrm{c}}$ & $4^{\mathrm{c}}$ & $1^{\mathrm{d}}$ \\
Amylase & $8^{\mathrm{a}}$ & $7^{\mathrm{a}}$ & $5^{\mathrm{b}}$ & $4^{\mathrm{bc}}$ & $3^{\mathrm{cd}}$ & $2^{\mathrm{d}}$ & $3^{\mathrm{cd}}$ & $5^{\mathrm{b}}$ \\
Retrogradation & $8^{\mathrm{a}}$ & $8^{\mathrm{a}}$ & $7^{\mathrm{ab}}$ & $6^{\mathrm{bc}}$ & $6^{\mathrm{bc}}$ & $5^{\mathrm{c}}$ & $5^{\mathrm{c}}$ & $4^{\mathrm{cd}}$ \\
\hline
\end{tabular}

CF- Cassava flour; the indices are from 0 to 9.

Figures with different superscripts along the row are significantly different at $\mathrm{p}<0.05$. A difference of 1 point on the Profiler is not a significant difference.

Mixolab indices indicated that water absorption increased with increase in cassava flour at more than $40 \%$ inclusion level. Addition of cassava flour to wheat flour increases starch and fibre contents, thereby increasing water absorption potential (Olubunmi et al., 2015). Khan et al. (2019) reported an increase in water absorption in wheat flour on addition of pumpkin flour, which was attributed to the increase in fibre content of the resulting flour. Mixing index decreased with blends containing $40 \%$ and more cassava flour. Mixing index represents the properties of the composite flour during mixing at $30^{\circ} \mathrm{C}$ and accounts for stability, dough development time and protein weakening (Mixolab Applications Handbook, 2012). However, cassava flour dilutes the wheat gluten thus reducing the dough stability. The gluten index was not much affected by the addition of cassava flour, which implies that starch may behave as gluten in food. The viscosity index decreased significantly $(p<0.05)$ with the addition of more than $30 \%$ cassava flour. This implies that the hot dough had reduced viscosity with inclusion of cassava in the composite flour, possibly due to the higher amylase activity in cassava flour compared to wheat flour.

The amylase index decreased significantly ( $\mathrm{p}<0.05$ ) with the addition of more than $20 \%$ cassava flour. This indicates that dough containing cassava flour had a higher amylase activity than pure wheat dough, and thus a higher rate of amylolysis. This is contradictory to the low diastatic activity of cassava flour and hence poor bakery performance reported by Lu et al. (2019). The retrogradation index reduced significantly ( $\mathrm{p}<0.05$ ) with the addition of more than $40 \%$ cassava flour. Starch retrogradation is a process in which disaggregated amylose and amylopectin chains in a gelatinized starch paste reassociate to form more ordered structures. It plays a major role in the staling of bread, which can cause reduced shelf-life and consumer acceptance and leads to significant waste and hence, economic losses to the baker. The results from this study therefore imply that addition of cassava flour could result in products with a longer shelf life than their counterparts made from pure wheat flour.

\subsection{Mixolab Properties of Wheat-cassava Composite Flour}

The mixolab results showed that water absorption ranged from 57.5 to $64.0 \%$; dough development time ranged from 0.90 to $1.46 \mathrm{~min}$; dough stability ranged from 4.60 to $9.30 \mathrm{~min}$; $\mathrm{C} 1$ ranged from 1.088 to $1.158 \mathrm{Nm}$; $\mathrm{C} 2$ ranged from 0.401 to $0.492 \mathrm{Nm}$; C3 ranged from1.373 to $1.945 \mathrm{Nm}$; 4 ranged from 1.150 to $1.788 \mathrm{Nm}$ and $\mathrm{C} 5$ ranged from 1.906 to $3.001 \mathrm{Nm}$ (Table 3; Figure 2).

There was a significant $(\mathrm{p}<0.05)$ increase in water absorption by wheat-cassava blend at a substitution level of $30 \%$ and above. $\mathrm{C} 1$, which determines water absorption/dough development, did not exhibit significant variations with increase in the concentration of cassava flour in the composite flour/dough. Water absorption influences dough yield, therefore these results suggest that inclusion of cassava flour in bread making could be profitable. Increase in WAC may be due to the high amount of starch (broken starch) and fibre in cassava flour (Kumar et al., 2015; Manano et al., 2017; Khan et al., 2019). Xhabiri et al. (2016) reported increased water absorption of wheat flour with the addition of wheat bran to the flour which increased the amount of fibre in the composite dough.

Dough development time (DDT) of pure wheat flour was low (1.46 min), signifying a weak flour (Dhaka et al., 2012; Dhaka and Khatkar, 2013). The DDT reduced significantly $(\mathrm{p}<0.05)$ on addition of more than $20 \%$ cassava flour. Xhabiri et al. (2016) reported increased dough development time of wheat flour with the addition of wheat bran.

The dough stability of pure wheat $(9.3 \mathrm{~min})$ obtained in this research implies that the wheat used exhibits characteristics of strong flour (Dhaka et al., 2012). The longer the mixing time the more the flour is said to be 
"strong" (Sabovics et al., 2011). Koksel et al. (2009) reported stability of 6 min 39 s for medium strong bread wheat flour. Dough stability, which is a measure of dough resistance to mixing and kneading, reduced significantly $(\mathrm{p}<0.05)$ above $30 \%$ substitution of wheat with cassava flour. Xhabiri et al. (2016) reported increased dough stability with addition of bran to wheat flour in some wheat varieties and decreased stability in other varieties. The increase in dough stability may be attributed to increased interaction between hydroxyl groups of the fibre molecules and water to form hydrogen bonds.

The protein quality, represented by $\mathrm{C} 2$ (the maximum torque attained when the dough undergoes mixing as well as heating), is an indicator of the quality and stability of wheat protein network to thermal weakening. The $\mathrm{C} 2$ values were greater than $0.4 \mathrm{Nm}$ in all the blends, indicating that all the flour blends were moderate and similar in gluten strength (Sabovics et al., 2011) and the subsequent doughs produced were moderately tolerant to mixing (Koksel et al. 2009). It is worth noting that the inclusion of cassava flour in the wheat flour did not significantly ( $>0.05$ ) influence this parameter (Table 3). Olubunmi et al. (2015) reported increased values of C2 for wheat - cassava composite flour with the addition of coconut fibre.

Table 3. Mixolab properties of wheat-cassava composite flour (14 moisture content basis)

\begin{tabular}{|c|c|c|c|c|c|c|c|c|}
\hline \multicolumn{9}{|c|}{ Proportion of cassava in flour blend, $\%$} \\
\hline Mixolab properties & $0 \% \mathrm{CF}$ & $10 \% \mathrm{CF}$ & $20 \% \mathrm{CF}$ & $30 \% \mathrm{CF}$ & $40 \% \mathrm{CF}$ & $50 \% \mathrm{CF}$ & $60 \% \mathrm{CF}$ & $100 \% \mathrm{CF}$ \\
\hline WA $(\%)$ & $57.5 \pm 0.10^{\mathrm{a}}$ & $57.5 \pm 0.10^{\mathrm{a}}$ & $57.0 \pm 0.10^{\mathrm{a}}$ & $58.5 \pm 0.20^{\mathrm{b}}$ & $60.5 \pm 0.20^{\mathrm{c}}$ & $62.5 \pm 0.20^{\mathrm{d}}$ & $64.0 \pm 0.20^{\mathrm{e}}$ & $68.5 \pm 0.20^{\mathrm{f}}$ \\
\hline DDT (min) & $1.46 \pm 0.04^{\mathrm{a}}$ & $1.365 \pm 0.02^{\mathrm{a}}$ & $1.283 \pm 0.19^{\mathrm{a}}$ & $0.840 \pm 0.10^{\mathrm{b}}$ & $0.800 \pm 0.02^{\mathrm{b}}$ & $0.793 \pm 0.03^{\mathrm{b}}$ & $0.900 \pm 0.02^{\mathrm{b}}$ & $1.963 \pm 0.82^{\mathrm{a}}$ \\
\hline Stability (min) & $9.30 \pm 0.10^{\mathrm{a}}$ & $9.45 \pm 0.05^{\mathrm{a}}$ & $9.35 \pm 0.05^{\mathrm{a}}$ & $9.03 \pm 0.35^{\mathrm{a}}$ & $4.87 \pm 1.05^{\mathrm{b}}$ & $3.90 \pm 0.40^{\mathrm{b}}$ & $4.60 \pm 0.20^{\mathrm{b}}$ & $7.10 \pm 1.10^{\mathrm{c}}$ \\
\hline $\mathrm{C} 1(\mathrm{Nm})$ & $1.139 \pm 0.02$ & $1.101 \pm 0.00$ & $1.158 \pm 0.06$ & $1.138 \pm 0.03$ & $1.134 \pm 0.05$ & $1.088 \pm 0.02$ & $1.173 \pm 0.02$ & $1.147 \pm 0.02$ \\
\hline $\mathrm{C} 2(\mathrm{Nm})$ & $0.486 \pm 0.01$ & $0.478 \pm 0.00$ & $0.492 \pm 0.03$ & $0.464 \pm 0.03$ & $0.420 \pm 0.01$ & $0.432 \pm 0.06$ & $0.401 \pm 0.01$ & $0.490 \pm 0.00$ \\
\hline $\mathrm{C} 3(\mathrm{Nm})$ & $1.913 \pm 0.05^{\mathrm{a}}$ & $1.934 \pm 0.08^{\mathrm{a}}$ & $1.945 \pm 0.02^{\mathrm{a}}$ & $1.921 \pm 0.02^{\mathrm{a}}$ & $1.810 \pm 0.02^{\mathrm{ab}}$ & $1.687 \pm 0.01^{\mathrm{b}}$ & $1.583 \pm 0.05^{\mathrm{b}}$ & $1.373 \pm 0.02^{\mathrm{c}}$ \\
\hline $\mathrm{C} 4(\mathrm{Nm})$ & $1.788 \pm 0.10^{\mathrm{a}}$ & $1.679 \pm 0.15^{\mathrm{ab}}$ & $1.606 \pm 0.03^{\mathrm{ab}}$ & $1.546 \pm 0.03^{\mathrm{b}}$ & $1.416 \pm 0.02^{\text {bce }}$ & $1.305 \pm 0.01^{\text {bcdef }}$ & $1.250 \pm 0.05^{\mathrm{ef}}$ & $1.150 \pm 0.00^{\mathrm{f}}$ \\
\hline $\mathrm{C} 5(\mathrm{Nm})$ & $3.001 \pm 0.29^{\mathrm{a}}$ & $2.789 \pm 0.28^{\mathrm{a}}$ & $2.635 \pm 0.08^{\mathrm{ab}}$ & $2.505 \pm 0.02^{\mathrm{abcd}}$ & $2.239 \pm 0.04^{\mathrm{bcd}}$ & $2.051 \pm 0.01^{\mathrm{ce}}$ & $1.989 \pm 0.08^{\text {cde }}$ & $1.906 \pm 0.01^{\mathrm{ebcd}}$ \\
\hline
\end{tabular}

The values are means \pm SD of triplicate independent determinations. Values with different superscripts along the row have means which are significantly different at $\mathrm{p}<0.05$.

$\mathrm{CF}$ - cassava flour; WA - water absorption; DDT - dough development time; C1 - determines water absorption; C2 - measures protein weakening as a function of mechanical work and temperature; C3 - measures starch gelatinization; C4 - measures hot gel stability; C5 measures starch retrogradation in the cooling phase.

The viscosity of the dough (C3) in this study was not significantly ( $p>0.05)$ different for pure wheat and composite flours up to $30 \%$ substitution level but decreased with the addition of more than $40 \%$ cassava flour. Olubunmi et al. (2015) reported general decrease in the value of C3 with the addition of coconut fibre to wheat-cassava composite flour. This indicates that amylase activity and starch quality were not significantly affected by the addition of up to $40 \%$ cassava flour to wheat flour (Sabovics et al., 2011).

The measure of hot gel stability (C4), decreased with the addition of cassava flour to wheat flour. However, the decrease was significant $(\mathrm{p}<0.05)$ at $30 \%$ substitution level and above. This implies low amylase activity of the composite flours on heating (Sabovics et al., 2011). The measure of starch gelling and retrogradation in the cooling phase (C5) decreased slightly, with further significant decrease $(\mathrm{p}<0.05)$, with the addition of more than $30 \%$ cassava flour. This indicates low starch retrogradation (the main origin of staling in baked cereal products) during the cooling period which corresponds to a long shelf life of the end product (Sabovics et al., 2011). Xhabiri et al. (2016) reported decreased value of C5 with the increase of wheat bran in wheat flour. Olubunmi et al. (2015) reported decreased C5 value with addition of coconut fibre in wheat-cassava composite flour. The results reported by Xhibiri (2016) and Olubunmi (2015) corroborate well with the findings of this study, and could mean that the fibre in cassava flour is the major cause of the decrease in C5. Manano et al (2018) however, reported low fibre contents in cassava flour from cassava varieties used in this study. 


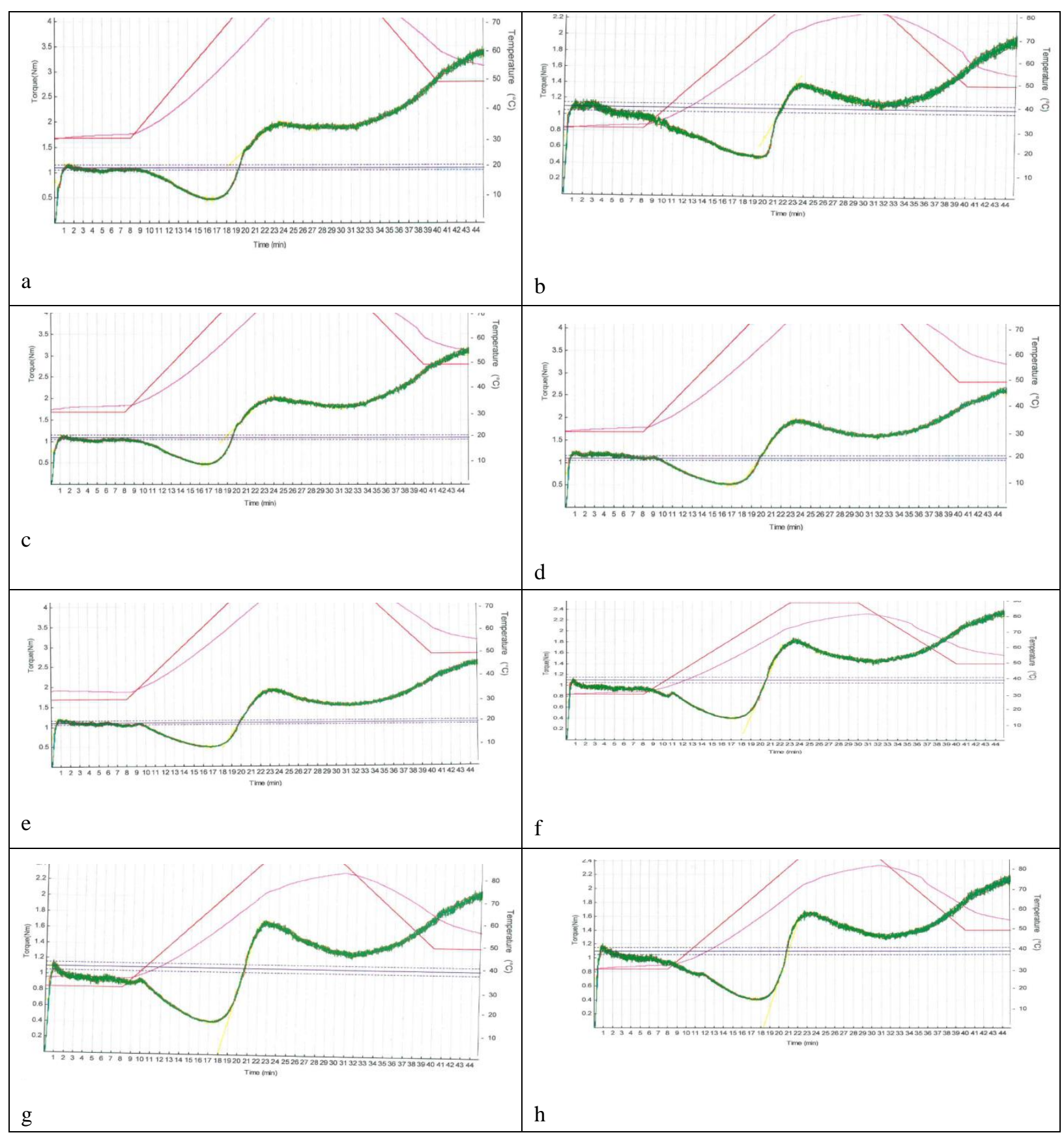

Figure 2. Mixolab curves for flour blends with different concentrations of cassava flour (CF): $0 \% \mathrm{CF}$ (a), $100 \%$ CF (b), $10 \%$ CF (c), $20 \%$ CF (d), 30\% CF (e), $40 \%$ CF (f), $50 \%$ CF (g) and $60 \%$ CF (h)

\subsection{Alveograph Properties of Wheat-cassava Composite Flour}

The Alveograph results showed that tenacity/elasticity (P) ranged from 29 to $117 \mathrm{~mm} \mathrm{H}_{2} \mathrm{O}$; dough extensibility (L) ranged from 32 to $120 \mathrm{~mm}$; ratio of tenacity to extensibility (P/L) ranged from 0.40 to 3.340 ; dough blowing index $(\mathrm{G})$ ranged from 12.60 to 24.30; work/deformation energy ranged from 63 to $210 \mathrm{x} 10^{-4} \mathrm{~J}$ and flexibility/elasticity index (Ie) ranged from 0 to $50.5 \%$ (Table 4). Addition of cassava flour up to $30 \%$ inclusion level significantly $(\mathrm{p}<0.05)$ increased dough elasticity/tenacity $(\mathrm{P})$, after which the elasticity significantly reduced $(\mathrm{p}<0.05)$. Cassava flour addition did not show a particular pattern on dough extensibility (L), first a decrease up to $20 \%$ inclusion level, then an increase and a leveling off. The $\mathrm{P} / \mathrm{L}$ ratio showed significant ( $\mathrm{p}<$ 0.05 ) increase at $10 \%$ and $20 \%$ inclusion levels of cassava flour in the composite dough, then a decrease and leveling off at $30 \%$ and more cassava inclusion levels. The swelling index (G) reduced with the addition of $10 \%$ and $20 \%$ cassava flour but increased at higher levels of incorporation of cassava flour $(>20 \%)$. The 
deformation energy/baking strength $(\mathrm{W})$ showed significant $(\mathrm{p}<0.05)$ decrease with the addition of cassava flour except at $40 \%$ inclusion level.

Table 4. Alveograph properties of wheat-cassava composite flour (14\% moisture content basis)

\begin{tabular}{llllllll}
\hline \multicolumn{2}{l}{ Proportion of cassava in flour blend, \% } & \multicolumn{7}{l}{} \\
\hline Alveograph properties & $0 \% \mathrm{CF}$ & $10 \% \mathrm{CF}$ & $20 \% \mathrm{CF}$ & $30 \% \mathrm{CF}$ & $40 \% \mathrm{CF}$ & $50 \% \mathrm{CF}$ & $60 \% \mathrm{CF}$ \\
\hline $\mathrm{P}\left(\mathrm{mmH}_{2} \mathrm{O}\right)$ & $96 \pm 2.0^{\mathrm{a}}$ & $107 \pm 3.0^{\mathrm{b}}$ & $117 \pm 3.5^{\mathrm{c}}$ & $104 \pm 3.0^{\mathrm{ab}}$ & $78 \pm 2.0^{\mathrm{d}}$ & $54 \pm 2.0^{\mathrm{e}}$ & $29 \pm 2.0^{\mathrm{f}}$ \\
$\mathrm{L}(\mathrm{mm})$ & $58 \pm 2.0^{\mathrm{a}}$ & $32 \pm 2.0^{\mathrm{b}}$ & $46 \pm 2.0^{\mathrm{c}}$ & $120 \pm 2.0^{\mathrm{d}}$ & $98 \pm 2.0^{\mathrm{e}}$ & $58 \pm 2^{\mathrm{a}}$ & $73 \pm 1.0^{\mathrm{f}}$ \\
$\mathrm{P} / \mathrm{L}$ & $1.433 \pm 0.38^{\mathrm{a}}$ & $3.340 \pm 0.02^{\mathrm{b}}$ & $2.540 \pm 0.02^{\mathrm{c}}$ & $0.870 \pm 0.02^{\mathrm{d}}$ & $0.8 \pm 0.02^{\mathrm{d}}$ & $0.93 \pm 0.02^{\mathrm{d}}$ & $0.40 \pm 0.02^{\mathrm{e}}$ \\
$\mathrm{G}$ & $16.90 \pm 0.02^{\mathrm{ab}}$ & $12.60 \pm 0.20^{\mathrm{b}}$ & $15.10 \pm 0.02^{\mathrm{ab}}$ & $24.30 \pm 0.20^{\mathrm{c}}$ & $22 \pm 0.20^{\mathrm{c}}$ & $16.9 \pm 0.20^{\mathrm{ab}}$ & $19.0 \pm 2.00^{\mathrm{a}}$ \\
$\mathrm{W} \mathrm{x} 10^{-4} \mathrm{~J}$ & $205 \pm 2.0^{\mathrm{a}}$ & $142 \pm 2.0^{\mathrm{b}}$ & $124 \pm 2.0^{\mathrm{c}}$ & $189 \pm 2.0^{\mathrm{d}}$ & $210 \pm 2.0^{\mathrm{a}}$ & $93 \pm 2.0^{\mathrm{e}}$ & $63 \pm 2.0^{\mathrm{f}}$ \\
$I e(\%)$ & $50.5 \pm 0.02^{\mathrm{a}}$ & $0 \pm 0.00^{\mathrm{b}}$ & $0 \pm 0.00^{\mathrm{b}}$ & $16 \pm 0.20^{\mathrm{c}}$ & $42.2 \pm 0.20^{\mathrm{d}}$ & $30.4 \pm 0.02^{\mathrm{e}}$ & $39.9 \pm 0.02^{\mathrm{f}}$ \\
\hline
\end{tabular}

The values are mean \pm SD of triplicate determinations. Values with different superscripts along the row have means which are significantly different at $\mathrm{p}<0.05$

$\mathrm{P}$ - maximum over pressure (resistance to extension, elasticity, tenacity); L - dough extensibility; G - dough blowing (swelling) index; W work (deformation energy) $\left(10^{-4} \mathrm{~J}\right)$; Ie - flexibility (elasticity) index; $\mathrm{CF}$ - cassava flour

Khan et al. (2019) reported an increase in tenacity (P) of pumpkin/wheat flour blends. The blends, however, had increased content of fibre than carbohydrates. Based on flour classification according to Koksel et al. (2009), the tenacity observed in this research $\left(78 \mathrm{~mm} \mathrm{H}_{2} \mathrm{O}\right)$ at $40 \%$ cassava flour inclusion was similar to that of medium strong wheat $\left(73 \mathrm{~mm} \mathrm{H}_{2} \mathrm{O}\right)$. Khan et al. (2019) reported a decrease in the extensibility of the dough from pumpkin-wheat flour composite. The $\mathrm{P} / \mathrm{L}$ ratio showed significant $(\mathrm{p}<0.05)$ increase at $10 \%$ and $20 \%$ inclusion levels of cassava flour in the composite dough, then a decrease and leveling off at $30 \%$ and more cassava inclusion levels. The $\mathrm{P} / \mathrm{L}$ ratio observed in this study at cassava concentration of $50 \%(0.93)$ was similar to the $\mathrm{P} / \mathrm{L}$ ratio of a medium strong wheat (Koksel et al., 2009).

The swelling indices for pure wheat and wheat-cassava blends in this research (12.6 to 24.3) were similar to that of medium strong bread wheat (23.1) reported by (Koksel et al. (2009). Moradi et al. (2016) reported a reduction in deformation energy (W), swelling index $(\mathrm{G})$ and elasticity (Ie) with increasing bran (fibre) content of flour. Khan et al. (2019) reported a decrease in baking strength with addition of pumpkin flour to wheat flour. The deformation energy of $210 \times 10^{-4} \mathrm{~J}$ observed in this study at the concentration of $40 \%$ cassava flour was similar to that reported for medium strong bread wheat $\left(214 \times 10^{-4} \mathrm{~J}\right.$ ) (Koksel et al., 2009). Callejo et al. (2009) reported increase in $\mathrm{P}$, while $\mathrm{L}$ and $\mathrm{W}$ decreased with increase in rye content of wheat-rye flour blends, probably due to the decrease of gluten content of the blends.

Macedo et al. (2020) argued that from the P/L ratio values, it is possible to know about the elastic resistance of the dough to biaxial extension and the potential to produce bread. When the value is within the range of 0.40 to 0.80 , dough has balanced gluten and is suitable to produce breads, while a $\mathrm{P} / \mathrm{L}$ value lower than 0.40 indicates very extendable dough. Higher $\mathrm{P} / \mathrm{L}$ values, e.g. 1.50, are indicators of very strong doughs not suitable for bread making (Macedo et al., 2020). The P/L values in this research ranged from 1.43 for pure wheat flour to 2.45 at $20 \%$ cassava substitution level and 3.34 at $10 \%$ cassava substitution level, making these composite flour doughs too strong and not suitable for bread production. The P/L values for composite flour doughs at $30 \%$, $40 \%, 50 \%$ and $60 \%$ substitution levels were $0.87,0.80,0.93$ and 0.40 respectively, showing their suitability for bread making. This may be very contradictory. Hruskova and Faměra (2003) reported P/L of commercial wheat flours ranging from 0.60 to 1.12 , and energy (W) ranging from $161.10^{-4} \mathrm{~J}$ (weak flour) to $271.10^{-4} \mathrm{~J}$ (strong flour). Based on these ranges, wheat-cassava composite flours in this study were equivalent to weak (at $60 \%$ cassava), moderately strong flours (at 30 to $50 \%$ cassava), and very strong flours (at 10 and $20 \%$ cassava), which implies that composite flour of $50 \%$ cassava inclusion level is as good as composite flour of $30 \%$ cassava inclusion in bread making.

\subsection{Consistograph Properties of Wheat-cassava Composite Flour}

Results from consistograph showed that water absorption capacity of flours ranged from 48 to $55.6 \%$ and maximum pressure ranged from 917 to $2819 \mathrm{mb}$ (Table 5). According to the consistograph, addition of cassava flour above $30 \%$ significantly $(\mathrm{p}<0.05)$ decreased the water absorption capacity and maximum pressure of the wheat - cassava flour blend. Maximum pressure decreased significantly $(p<0.05)$ with the addition of cassava flour to wheat flour. 
Table 5. Consistograph properties of wheat-cassava composite flour (14\% moisture content basis)

\begin{tabular}{|c|c|c|c|c|c|c|c|}
\hline \multicolumn{8}{|c|}{ Proportion of cassava in flour blends } \\
\hline Consistograph properties & $0 \% \mathrm{CF}$ & $10 \% \mathrm{CF}$ & $20 \% \mathrm{CF}$ & $30 \% \mathrm{CF}$ & $40 \% \mathrm{CF}$ & $50 \% \mathrm{CF}$ & $60 \% \mathrm{CF}$ \\
\hline WAC $(\%)$ & $55.6 \pm 1.0^{\mathrm{a}}$ & $54.6 \pm 1.0^{\mathrm{ab}}$ & $54.2 \pm 1.0^{\mathrm{ab}}$ & $53.4 \pm 1.0^{\mathrm{b}}$ & $51.3 \pm 1.0^{\mathrm{bc}}$ & $49.2 \pm 1.0^{\mathrm{c}}$ & $48 \pm 1.0^{\mathrm{c}}$ \\
\hline PrMax (mbar) & $2819 \pm 1.0^{\mathrm{a}}$ & $2396 \pm 2.0^{\mathrm{b}}$ & $2315 \pm 2.0^{\mathrm{c}}$ & $2136 \pm 2.0^{\mathrm{d}}$ & $1675 \pm 2.0^{\mathrm{e}}$ & $1198 \pm 2.0^{\mathrm{f}}$ & $917 \pm 3.0^{\mathrm{g}}$ \\
\hline
\end{tabular}

The values are mean \pm SD of triplicate determinations. Values with different superscripts along the row have means which are significantly different at $\mathrm{p}<0.05$

PrMax - maximum pressure; WAC - water absorption capacity; $\mathrm{CF}$ - cassava flour

The reduction in water absorption capacity may be attributed to dilution of the wheat gluten by starch and fibre in the cassava flour (Callejo et al., 2009; Kumar et al., 2015), which inhibits the gluten network structure. The presence of added starch and fibre also leads to increased competition for the available water among the different moieties of the flour (Callejo et al., 2009; Olubunmi et al., 2015). Kumar et al. (2015) observed reduction in water absorption capacity of wheat on addition of multigrain premixes.

The decrease in maximum pressure implies a decrease in the tolerance or stability of the dough. Such dough shows low extensibility and low tensile strength, which produces undeveloped bread (David et al., 2014). The dough elasticity and extensibility in this study were not high enough and therefore, such dough may not be good for bread making. Dough with high elasticity and extensibility produces loose bread with developed volume and a core containing pores with thin walls (David et al., 2014). This was evident in this study, whereby as cassava substitution levels increased, the bread volume reduced. Callejo et al. (2009) reported a decrease in water absorption capacity and maximum pressure in composite wheat-rye flours, similar to results obtained in this study.

\subsection{Quality Evaluation of Wheat-cassava Composite Bread}

\subsubsection{Bread Volume and Bread Density}

Bread volume ranged from 516.7 to $631.0 \mathrm{~cm}^{3}$. Loaf density ranged from 0.49 to $0.636 \mathrm{~g} / \mathrm{cm}^{3}$. Specific bread volume ranged from 1.571 to $2.065 \mathrm{~cm}^{3} / \mathrm{g}$. Moisture loss ranged from 6.38 to $14.98 \%$ (Table 6). The volume of bread made from wheat - cassava composite flour decreased significantly $(\mathrm{p}<0.05)$ with concentrations of cassava flour more than $20 \%$. The density of bread made from wheat - cassava composite flour increased significantly $(\mathrm{p}<0.05)$ with increasing proportion of cassava flour in the composite. Water loss was highest in $100 \%$ wheat bread and significantly $(\mathrm{p}<0.05)$ differed from water loss from composite breads.

In bread consuming communities, loaf volume is the principal component of, and is of paramount importance to, bread quality evaluation. This is a vital aspect of the consumer's perception of value, because in bread and other leavened goods, higher volume, for the same weight, is invariably associated with more aerated crumb and superior texture. Loaf volume is therefore, probably the most important external characteristic of bread since it provides a quantitative measurement of baking performance (Olubunmi et al., 2015). Based on critical observation, in Uganda bread is rated by the consumer in terms of appearance, weight, volume and brand. This may be attested by the fact that different bakeries in Uganda produce bread loaves with different appearances, crust colour, volumes, and crumb texture, yet all are able to survive in the competitive market.

Higher loaf volume has positive economic effect on bread at the retail end since consumers falsely get attracted to bread loaf with bigger volume with the belief that it has more substance for the same price.

Table 6. Physical evaluation of bread made from cassava-wheat composite flours

\begin{tabular}{llllllll}
\hline \multicolumn{2}{l}{ Proportion of cassava in bread flour, \% } \\
\hline Parameter & $0 \% \mathrm{CF}$ & $10 \% \mathrm{CF}$ & $20 \% \mathrm{CF}$ & $30 \% \mathrm{CF}$ & $40 \% \mathrm{CF}$ & $50 \% \mathrm{CF}$ & $60 \% \mathrm{CF}$ \\
\hline Bread volume $\mathrm{cm}^{3}$ & $631.0 \pm 6.6^{\mathrm{a}}$ & $627.7 \pm 2.5^{\mathrm{a}}$ & $657.7 \pm 2.5^{\mathrm{b}}$ & $532.3 \pm 2.6^{\mathrm{c}}$ & $552.3 \pm 2.5^{\mathrm{d}}$ & $520.7 \pm 1.2^{\mathrm{c}}$ & $516.7 \pm 2.9^{\mathrm{e}}$ \\
Loaf weight, $\mathrm{g}$ & $306 \pm 0.3$ & $324.3 \pm 1.4$ & $330.6 \pm 2.2$ & $326.1 \pm 1.6$ & $328.9 \pm 1.2$ & $331.0 \pm 0.5$ & $329.2 \pm 0.5$ \\
Bread density, $\mathrm{g} / \mathrm{cm}^{3}$ & $0.49 \pm 0.0^{\mathrm{a}}$ & $0.518 \pm 0.0^{\mathrm{b}}$ & $0.506 \pm 0.0^{\mathrm{c}}$ & $0.613 \pm 0.0^{\mathrm{d}}$ & $0.6 \pm 0.0^{\mathrm{d}}$ & $0.636 \pm 0.0^{\mathrm{e}}$ & $0.636 \pm 0.0^{\mathrm{e}}$ \\
Specific vol, $\mathrm{cm}^{3} / \mathrm{g}$ & $2.065 \pm 0.0^{\mathrm{a}}$ & $1.942 \pm 0.0^{\mathrm{a}}$ & $1.659 \pm 0.6^{\mathrm{b}}$ & $1.628 \pm 0.0^{\mathrm{b}}$ & $1.619 \pm 0.0^{\mathrm{b}}$ & $1.571 \pm 0.0^{\mathrm{c}}$ & $1.574 \pm 0.0^{\mathrm{c}}$ \\
Moisture loss, $\%$ & $14.98 \pm 0.5^{\mathrm{a}}$ & $6.38 \pm 2.5^{\mathrm{b}}$ & $9.87 \pm 2.0^{\mathrm{c}}$ & $8.43 \pm 1.1^{\mathrm{d}}$ & $9.63 \pm 1.2^{\mathrm{c}}$ & $8.56 \pm 0.8^{\mathrm{d}}$ & $9.62 \pm 0.5^{\mathrm{c}}$ \\
\hline
\end{tabular}

Results are the averages of three independent determinations \pm SD. Means within a row with different superscripts are significantly different at $p<0.05$.

The variation in loaf volume in this study could be attributed to the substitution of wheat with cassava flour, which leads to dilution of the wheat structural protein, gluten. The low gluten level may negatively affect the 
dough viscoelastic properties, and thus a reduction in loaf volume and specific loaf volume. Gluten has the ability to form a three-dimensional viscoelastic network responsible for gas retention in the dough (Kent and Evers, 1994; Aboaba and Obakpolor, 2010). While gluten is sufficiently extensible to allow the dough to rise, it must be strong enough to prevent gas escaping too readily, which may lead to collapse of the loaf (Kent and Evers, 1994). Cassava flour contains about $1.1 \%$ crude fibre (Manano et al., 2018) compared to approximately $0.5 \%$ crude fibre in wheat (Khan et al., 2019). The elevated fibre content in the wheat-cassava composite flour due to incorporation of cassava flour may puncture expanding gas cells during fermentation leading to reduced loaf volumes (Oladunmoye et al., 2010; Olubunmi et al., 2015).

The variation in loaf density could be attributed to different rates of gas evolution and retention. Eriksson et al. (2014) observed decrease in bread volumes made with $20 \%$ and $30 \%$ cassava-wheat composite flours from some cassava varieties. As the bread volume decreased with increasing levels of cassava flour substitution, the bread density concomitantly increased. Studies showed that loaf volume is affected by the quantity and quality of protein in the flour used for baking and also by proofing time, baking time and baking temperature (Bushuk, Briggs and Shebeski, 1969; Veraverbeke and Delcour, 2002; Shittu, Raji and Sanni, 2007; Rózylo and Laskowski, 2011). Cassava flour lacks gluten-forming proteins and is therefore unable upon hydration to form the cohesive viscoelastic dough capable of forming the typical fixed open foam structure of bread (Aboaba and Obakpolor, 2010). Consequently, an increase in proportion of cassava flour in the composite dough reduces the gluten content. Gluten is responsible for dough elasticity, thus, an increased substitution with cassava flour would result in weaker and less elastic dough and a reduction in the leavening ability, resulting in bread with lower volume and higher density. According to Aboaba and Obakpolor (2010), an inclusion of cassava flour beyond $20 \%$ significantly reduces the leavening profile of dough made from wheat-cassava composite flour. The high water retention (low water loss) associated with increased cassava concentration in the composite flour/dough may be attributed to the high contents of fibre and starch present in cassava flour compared to wheat flour (Olubunmi et al., 2015). This leads to increased density of bread made from composite containing higher levels of cassava flour.

\subsubsection{Sensory Evaluation of Wheat-cassava Composite Bread}

Results from sensory evaluation showed that crust colour ranged from 4.13 to 6.88 ; taste ranged from 4.25 to 7.13; crumb texture ranged from 4.50 to 6.63 and overall acceptability ranged from 4.13 to 8.13 (Table 7). Incorporation of HQCF influenced the sensory quality attributes of bread. Bread made from $100 \%$ wheat flour was superior in all the quality attributes. Bread baked from $40 \%$ cassava flour recorded an overall acceptability of 5.75, slightly better than the hedonic scale of "neither like nor dislike" although significantly $(p<0.05)$ different from bread made from $100 \%$ wheat flour. Bread made from composite containing $20 \%$ cassava flour was not significantly $(\mathrm{p}>0.05)$ different from bread made from pure wheat with respect to crust colour, taste and crumb texture. The results obtained in this study imply that any bread made from wheat-cassava composite containing $20 \%$ or less cassava flour would be acceptable and those made from composite containing more than $20 \%$ cassava flour would fail in all the sensory parameters evaluated and overall acceptability.

Table 7. Sensory scores of bread made from wheat-cassava composite flours

\begin{tabular}{llllllll}
\hline \multicolumn{7}{l}{ Proportion of cassava in bread flour, \% } \\
\hline Parameter & $0 \%$ CF & $10 \%$ CF & $20 \%$ CF & $30 \%$ CF & $40 \%$ CF & $50 \%$ CF & $60 \%$ CF \\
\hline Crust colour & $6.88 \pm 1.96^{\mathrm{a}}$ & $6.38 \pm 1.41^{\mathrm{a}}$ & $6.63 \pm 1.41^{\mathrm{a}}$ & $4.88 \pm 0.99^{\mathrm{c}}$ & $5.38 \pm 0.92^{\mathrm{b}}$ & $4.13 \pm 1.25^{\mathrm{d}}$ & $4.63 \pm 1.77^{\mathrm{c}}$ \\
Taste & $7.13 \pm 1.55^{\mathrm{a}}$ & $6.38 \pm 1.85^{\mathrm{a}}$ & $6.25 \pm 1.75^{\mathrm{a}}$ & $4.88 \pm 1.46^{\mathrm{b}}$ & $4.63 \pm 1.69^{\mathrm{b}}$ & $4.5 \pm 1.0$ & $4.25 \pm 1.58^{\mathrm{b}}$ \\
Crumb texture & $6.5 \pm 1.69^{\mathrm{a}}$ & $6.63 \pm 1.85^{\mathrm{a}}$ & $6.5 \pm 1.93^{\mathrm{a}}$ & $5.13 \pm 1.89^{\mathrm{b}}$ & $5.63 \pm 1.85^{\mathrm{b}}$ & $4.50 \pm 2.20^{\mathrm{c}}$ & $4.63 \pm 2.13^{\mathrm{c}}$ \\
Overall Acceptabilty & $8.13 \pm 0.84^{\mathrm{a}}$ & $7.13 \pm 1.36^{\mathrm{ab}}$ & $6.00 \pm 1.51^{\mathrm{b}}$ & $5.50 \pm 1.60^{\mathrm{b}}$ & $5.75 \pm 1.28^{\mathrm{b}}$ & $4.13 \pm 1.73^{\mathrm{c}}$ & $4.5 \pm 1.31^{\mathrm{c}}$ \\
\hline
\end{tabular}

Results are the averages of twenty independent determinations. Means within a row with different superscript letters are significantly different at $p<0.05$.

The sensory scores decreased as more cassava flour was incorporated in the composite. The exception was with the crust colour and crumb texture of bread made with concentration of $40 \%$ cassava flour. The two sensory properties were superior to those of bread made from flour containing $30 \%$ cassava flour. The gluten forming protein of wheat determines the physical, sensory and textural quality of bread (Shittu et al., 2015). Important bread loaf properties that determine acceptability of bread are taste (sweetness), crumb texture (softness or elasticity), flavor, crumb structure (porosity), crust appearance and crumb colour (Shittu et al., 2015).

The observed rating for crust colour showed that supplementation of cassava flour in composite bread at levels higher than $20 \%$ had a detrimental effect on crust colour. Aboaba and Obakpolor (2010) similarly reported that 
bread made from composite flour containing 10 and $20 \%$ cassava flour were acceptable but bread made from 30 and $40 \%$ cassava inclusion were not accepted. Sampson (2020) however, reported that bread of acceptable crust colour was made from composite flour containing $30 \%$ cassava flour. Addition of cassava flour to wheat flour dilutes the wheat proteins, responsible for the Maillard reactions, one of the reactions which are responsible for the formation of brown colour during baking. This may imply that caramelisation process, which is also responsible for the formation of brown pigments during baking, is not the major process for the brown colour of baked products. Eddy et al. (2007) however, reported that the level of cassava flour inclusion in composite bread did not reduce the caramelisation process, although the maximum level of supplementation in their research was $30 \%$.

The rating for the taste of the breads containing more than $20 \%$ cassava flour was disliked by all the panelists, implying that the taste of the bread was affected by the level of supplementation of cassava flour in the composite breads. Sampson (2020) reported similar findings, while bread made from $30 \%$ cassava composite showed lower ratings. Eddy et al. (2007) however, reported an acceptable taste of bread produced from composite containing $30 \%$ cassava flour. Eleazu et al. (2014) reported that bread was produced from composite containing 10,20,30, and $40 \%$ cassava flour with mean taste scores not significantly different from that of the $100 \%$ wheat bread. The low mean scores for taste may be due to the dilution of gluten in the wheat flour. Gluten plays an important role in the overall sensory and structural characteristics of baked products (Lu et al., 2019). During baking, Maillard reactions produce volatile flavor compounds which make major contributions to the attractive flavor of bread. Likewise, the products of thermal decomposition of sugar molecules give rise to a range of flavor compounds that are associated with toast, as discussed by Coultate (1999). Inclusion of cassava in the composite flour, however dilutes the protein involved in Maillard reactions, but not the sugar content of flour. The pour taste of composite bread was thus the result of reduced concentration of flavor compounds arising from the reduced extent and rate of Maillard reaction.

The crumb texture of the bread was disliked by all the panelists at substitution level of more than $40 \%$. This implies that the level of supplementation of wheat with cassava flour influences the quality of dough that gives bread the texture consumers are familiar with. The results for breads from 10 and $20 \%$ substitution were comparable to that of the control, signifying the dependence of the quality of bread that can be produced from wheat-cassava composite flour. Eddy et al. (2007) reported similar findings, and stated that bread from flour containing 10 and $20 \%$ cassava flour had textures comparable to that of $100 \%$ wheat bread.

Mean scores for overall acceptability revealed that the quality of bread that can be made from wheat-cassava composite depends on the level of substitution. Bread made from composite containing 10 and $20 \%$ cassava flour were comparable to bread made from $100 \%$ wheat, but bread made from 30 and $40 \%$ cassava were neither liked nor disliked by the panelists though they had low scores for all the sensory parameters. The low mean scores for sensory attributes, crust colour, loaf texture and taste, of bread containing 30 and $40 \%$ cassava flour might be attributed to the poor binding power of cassava which made the binding of the dough difficult thereby affected the overall quality of the products and thus their acceptability (Aboaba and Obakpolor, 2010). These researchers suggested the use of bread improvers or the use of high percentage of fat and sugar in order to increase the level of incorporation of cassava in composite without grave changes in the resultant bread characteristics. Lu et al. (2019) suggested the use of hydrophilic colloids, such as xanthan gum, with hydrophilic characteristics to not only improve on the appearance, taste, colour, texture, mouthfeel and overall acceptability of the composite bread but also improve the overall quality of the bread to meet production requirements. This however, is likely to increase the price of the bread and thus still keep it unaffordable to many Ugandan communities. Eleazu et al. (2014) similarly reported that substitution of wheat flour with up to $20 \%$ cassava flour yielded bread samples with a general acceptability that was comparable to $100 \%$ wheat bread. Khalil et al. (2000) reported that the incorporation of $1 \%$ malt in wheat-cassava composite flour of 20 and $30 \%$ levels of substitution resulted in flour with good bread-making potential, improved $\alpha$ - amylase activity, and dough with good rheological properties which produced bread with sensory characteristics similar to bread obtained from $100 \%$ wheat.

A number of studies have been conducted to show the potential of cassava flour in bread making, and production of other baked products such as cakes and pastries. Some researchers recommended 5 to10\% substitution of wheat flour (Dendy et al., 1992; Giacco and Appolonia, 1977; Almazan, 1990; Defloor, 1995, Eddy et al., 2007; Aristizábal, Garcia, and Ospina 2017). Others recommended substitution levels of up to $30 \%$ (Defloor et al., 1993 and Jensen et al., 2015). Siyeni et al. (2004) suggested a $33 \%$ inclusion of HQCF in wheat flour for bread baking. Eduardo et al. (2014) produced bread with acceptable sensory qualities from cassava-maize-wheat composite flour at cassava inclusion level of $40 \%$. The quality of bread produced from composite flours is also influenced 
by the variety of cassava (Eggleston et al., 1993; Eduardo et al., 2013; Eriksson et al., 2014; Shittu et al., 2007), maturity of the cassava roots of the same variety (Defloor et al., 1994, 1995). Linus-Chibuezeh et al. (2017) however, found out that bread made from 10 to $30 \%$ cassava-wheat composite flours, irrespective of the cassava variety used, was of acceptable qualities.

The quality of the bread produced from cassava-wheat composite flours may also depend on the type of bread. Aryeetey et al. (2019) observed that cassava substitution levels of $20 \%$ for sugar bread and

$10 \%$ for tea bread were deemed culturally acceptable. Therefore, the taste to which a community is accustomed may play a big role in determining sensory acceptability of the levels of substitution of wheat with cassava in the products consumed.

The Federal Government of Nigeria (FGN) released a $40 \%$ cassava inclusion in wheat flour policy in 2012, mandating flour millers and bakers to incorporate $40 \%$ cassava flour into wheat flour meant for bread making, pasta and other confectionaries (Adeniji, 2013). This followed the successful development of bread containing 40\% cassava flour by the International Institute of Tropical Agriculture (Eleazu et al., 2014). Such a policy can be introduced in Uganda based on findings of this type of study, to encourage the use of cassava in the bakery and confectionery industry. There is however, the need to design appropriate processes and technologies to manufacture the products of choice.

\subsection{Correlation Analysis}

\subsubsection{Correlation between Dough Rheology and Sensory and Physicochemical Properties of Bread}

Correlations were determined between mixolab, alveograph, and consistograph parameters at constant hydration and bread quality characteristics to identify the instrumental parameters which could demonstrate the suitability of the instruments for estimating bread making quality of composite flour (Figure 3). The first two principal components F1 and F2 accounted for $78.72 \%$ of the variance (64.26 and $14.46 \%$ respectively). The third principal component accounted for $13.29 \%$ of the variance. The fourth principal component accounted for $5 \%$ of the variance. High relationships were shown within each of the following three groups of rheological parameters: mixolab DDT, C2, C3, C4 and C5, alveograph P, and consistograph WAC and PrMax. Any positive correlation would guide millers in producing the right composite flour, and bakers, in making bread of acceptable quality.

According to the PCA, overall acceptability of bread was positively correlated with the bread sensory characteristics crust colour $(r=0.905)$, taste $(r=0.914)$, and crumb texture $(r=0.891)$. Overall acceptability was also positively related to bread physical characteristics bread volume $(\mathrm{r}=0.790)$ and bread specific volume $(\mathrm{r}=$ $0.941)$, but negatively correlated with bread weight $(\mathrm{r}=-0.815)$, and bread density $(\mathrm{r}=-0.890)$.

Overall acceptability was positively related with mixolab parameters dough development time (DDT) $(r=0.585)$, dough stability $(r=0.749)$, protein weakening $(C 2)(r=0.732)$, starch gelatinization (C3)

$(\mathrm{r}=0.745)$, amylase activity $(\mathrm{C} 4)(\mathrm{r}=0.941)$ and starch gelling $(\mathrm{C} 5)(\mathrm{r}=0.945)$, but negatively correlated with water absorption (WA) $(r=0.801)$. Acceptability was positively correlated with alveograph parameters tenacity $(\mathrm{P})(\mathrm{r}=0.675)$ and deformation energy/work $(\mathrm{W})(\mathrm{r}=0.640)$ but negatively correlated with dough extensibility (L) $(\mathrm{r}=-0.324)$ and dough swelling index $(\mathrm{G})$

$(\mathrm{r}=-0.466)$. Acceptability was positively correlated with consistograph parameters maximum pressure (PrMax) $(\mathrm{r}=0.913)$ and water absorption capacity (WAC) $(\mathrm{r}=0.890)$.

The brown colour of bread crust is due to melanoidins formed by a non-enzymic browning reaction known as the Maillard reaction between amino acids, dextrins and reducing sugars, and products from the thermal decomposition of sugars (Kent and Evers, 1994; Coultate, 1999). The aroma of bread results from the interaction of reducing sugars and amino compounds, with the formation of aldehydes, alcohols, organic acids and esters. Caramelization also gives rise to a wide range of flavour compounds present in the bread crust. These complex reactions are favoured at low water activities when the reactants are more concentrated ( 0.8 to 0.3 for Maillard reaction) (Coultate, 1996). This explains the observation in this study that showed positive correlation between consistograph parameter water absorption capacity (WAC) and crust colour $(r=0.864)$ and negative correlation between crust colour and mixolab parameter water absorption (WA) $(r=-0.840)$.

The average scores for crumb texture decreased with increase in cassava flour concentration in the composite. Crumb texture was related to gluten network, kneading and hydration of flour. It was positively correlated with bread volume $(\mathrm{r}=0.956)$ and loaf specific volume $(\mathrm{r}=0.770)$, but negatively correlated with bread density $(\mathrm{r}=$ $-0.963)$ and loaf weight $(r=-0.495)$. Crumb texture was positively correlated with mixolab parameters dough 
development time (DDT) $(r=0.880)$, protein weakening $(C 2)(r=0.807)$, starch gelatinization $(C 3)(r=0.819)$, amylase activity (C4) $(r=0.890)$ and starch gelation (C5) $(r=0.889)$. It is, however negatively related to water absorption (WA) $(\mathrm{r}=-0.881)$. Crumb texture was positively correlated with alveograph parameters tenacity $(\mathrm{P})(\mathrm{r}$ $=0.803)$ and deformation energy/work $(\mathrm{W})(\mathrm{r}=0.476)$, but negatively correlated with dough extensibility $(\mathrm{L})(\mathrm{r}$ $=-0.498)$ and dough swelling index $(\mathrm{G})(\mathrm{r}=-0.648)$. Crumb structure was positively correlated with consistograph parameters water absorption capacity (WAC) $(\mathrm{r}=0.886)$ and maximum pressure (PrMax) $(\mathrm{r}=$ 0.878). Protein present in wheat yields gluten on hydration. The formed gluten is responsible for dough elasticity, strength and stability. Therefore, adequate water must be added to the flour to make dough of appropriate consistency. The absorbed water also increases the weight of the dough, which increases dough density. Addition of cassava flour to wheat flour dilutes the wheat flour gluten by increasing the amount of starch (damaged and undamaged). The added cassava flour in this study decreased mixing index which is responsible for stability, dough development time and protein weakening of the dough. Addition of cassava flour also increased amylase activity of the composite since cassava flour has been shown to possess higher amylase activity than wheat flour. The increased amylase activity should have increased the gassing properties of the composite dough and yielded sufficient sugars through diastatic action to support the activity of the yeast enzymes during fermentation and proofing (Kent and Evers, 1994). However, results showed that cassava flour addition to wheat flour instead produced bread with reduced volume, higher density and lower specific volume.

The specific loaf volume was found to be positively correlated with bread volume $(r=0.695)$, but negatively correlated with loaf weight $(\mathrm{r}=-0.867)$ and bread density $(\mathrm{r}=-0.818)$. Koksel et al (2009) reported significant correlation of bread volume with mixolab parameters starch gelatinization (C3), amylase activity (C4) and starch gelation (C5). Specific loaf volume was positively correlated with mixolab parameters dough development time (DDT) $(r=0.867)$, dough stability $(r=0.791)$, protein weakening $(C 2)(r=0.668)$, starch gelatinization $(C 4)(r=$ $0.587)$, amylase activity $(\mathrm{C} 4)(\mathrm{r}=0.871)$ and starch gelling $(\mathrm{C} 5)(\mathrm{r}=0.886)$, and negatively correlated with water absorption (WA) $(\mathrm{r}=-0.658)$. Dhaka et al (2012) reported a high positive correlation between specific loaf volume and mixolab parameters protein weakening (C2), dough stability and dough development time (DDT). Specific volume was positively correlated with alveograph parameters tenacity $(\mathrm{P})(\mathrm{r}=0.507)$ and deformation energy (W) $(r=0.464)$, but negatively correlated with extensibility $(\mathrm{L})(\mathrm{r}=-0.471)$ and dough swelling index $(\mathrm{G})$ $(\mathrm{r}=-0.565)$. Specific loaf volume was positively correlated with consistograph parameters water absorption capacity (WAC) $(\mathrm{r}=0.778)$ and maximum pressure (PrMax) $(\mathrm{r}=0.812)$.

Bread loaf with good/high specific volume indicates that enough bubble structure was created in the dough during mixing, adequate carbon dioxide was produced during fermentation to inflate the gas cells formed in the dough and the dough has the capacity to retain the gas. Gas retention is a property of flour gluten. The gluten should be extensible enough to allow the dough to rise and yet be strong enough to prevent gas escaping, which may lead to the collapse of the dough. The decrease in specific loaf volume with increase in cassava flour concentration in the composite flour observed in this study attested to the interference of cassava flour with formation of gluten network in the dough. The dough restricted the escape of moisture or retained moisture, leading to heavier loaves of high density and hence low loaf specific volume.

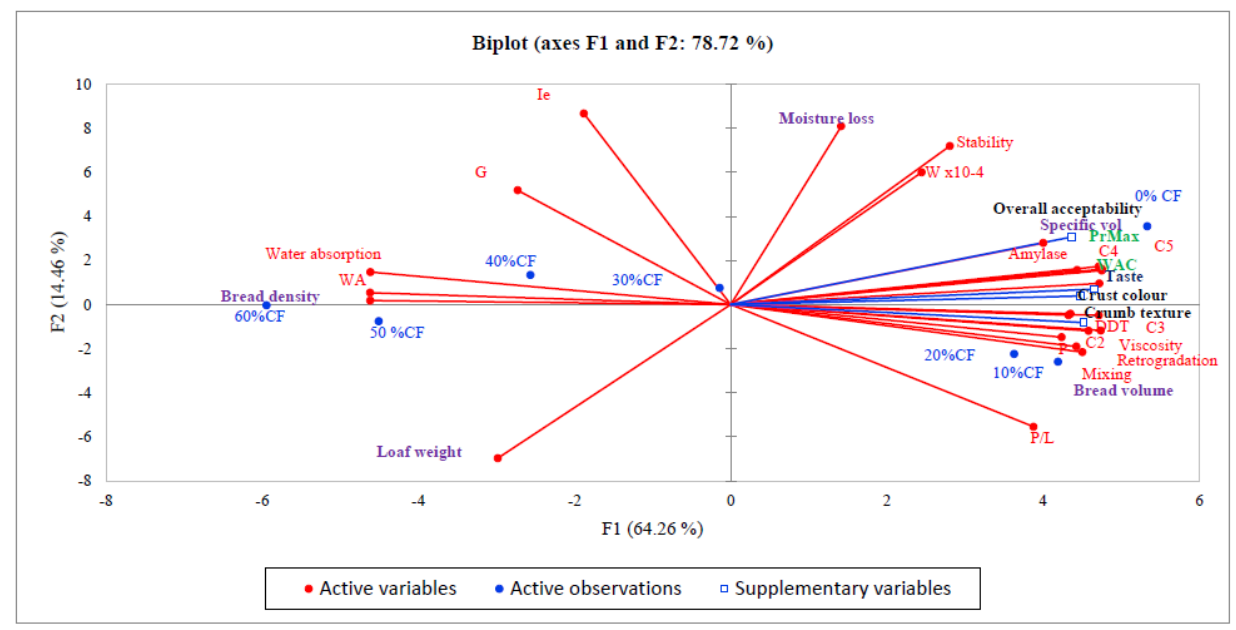

Figure 3. Principal component analysis of various rheological parameters of dough and sensory characteristics and physicochemical properties of bread 
WA-water absorption, G - dough swelling index, Ie - flexibility (elasticity) index, L - dough extensibility, Wdeformation energy,

P - tenacity, DDT - dough development time, WAC - water absorption capacity, C2 - protein weakening, C3 starch gelatinization, C4 - amylase activity, C5 - starch gelling

\section{Conclusion}

The results of the present study on rheological characteristics of dough were able to generate correlation between mixolab, alveograph and consistograph properties, bread making quality of flour/dough and bread quality parameters. Some dough rheological properties can be used as predictors of bead quality characteristics and this ability could be used to modify dough formulations depending on the characteristics desired in the final composite bread. Mixolab parameters protein weakening (C2), dough stability and dough development time (DDT) were found to be associated with specific loaf volume. Based on Mixolab, the study identified the right substitution level of wheat with cassava flour in the composite. The Mixolab proved to be a simple and effective tool for evaluating flour quality. The Mixolab can be used to identify protein and starch properties and thus predict the bread making quality of composite flours based on the dough stability and C2 values within a short time of only $45 \mathrm{~min}$.

The study showed that inclusion of cassava flour in wheat flour at varying levels reduced loaf volume and specific volume but increased bread density. Cassava inclusion negatively affected both physical and sensory qualities of bread. Despite effects on physical and sensory quality, sensory evaluation, supported by the PCA analysis, indicated that bread of acceptable quality can be produced from wheat-cassava composite flour containing not more than $30 \%$ cassava. Dough development time (DDT) of not less than 1 min and dough stability of not less than $9 \mathrm{~min}$ are the reccommended parameters for wheat-cassava composite flour which are likely to produce bread of acceptable quality. Alveograph parameters of tenacity $(\mathrm{P})$ of not less than $78 \mathrm{~mm} \mathrm{H}_{2} \mathrm{O}$ and deformation energy $(\mathrm{W})$ of not less than $124 \times 10^{-4} \mathrm{~J}$; and consistograph parameter of maximum pressure (PrMax) of not less than $1675 \mathrm{mb}$ are as well reccommended for processing of high quality cassava-wheat composite bread.

\section{Acknowledgments}

This work was supported by Research Grant from Kyambogo University, Kampala, Uganda. The authors acknowledge Mr. Kisenyi and the BIC laboratory for their technical support in mixolab analysis.

\section{Conflicts of Interest}

The authors have not declared any conflict of or competing interest.

\section{References}

American Association of Cereal Chemists (AACC). (2000). Approved methods of the American Association of Cereal Chemists (11th ed.). St. Paul, MN, USA.

Abass, A. B., Awoyale, W., Alenkhe, B., Malu, N., Asiru, B. W., Manyong, V., \& Sanginga, N. (2018). Can food technology innovation change the status of a food security crop? A review of cassava transformation into "bread" in Africa. Food Reviews International, 34(1), 87-102. https://doi.org/10.1080/87559129.2016.1239207

Aboaba, O. O., \& Obakpolor, E. A. (2010). The leavening ability of baker's yeast on dough prepared with composite flour (wheat/cassava). African Journal of Food Science, 4(6), 325-329. https://doi.org/10.5897/AJFS.9000289

Agunbiade, S. O., Ojezele, O. J., \& Eze, A. M. (2017). Maximizing the incorporation of cassava flour as an adjunct in bread baking in Nigeria. Chemistry International, 3(1), 92-96.

Almazan, A. M. (1990). Effect of Cassava Flour Variety and Concentration on Bread Loaf Quality. Cereal Chemistry, 67(1), 97-99.

Anjum, F. M., Khan, M. R., Din, A., Saeed, M., Pasha, I., \& Arshad, M. U. (2007). Wheat Gluten: High Molecular Weight Glutenin Subunits-Structure, Genetics, and Relation to Dough Elasticity. Journal of Food Science, 72(3), 56-63. https://doi.org/10.1111/j.1750-3841.2007.00292.x

AOAC. (1995). Association of Official Analytical Chemists (16th ed.). Official Methods of Analysis. Washington D.C., USA. 
Apea-Bah, F. B., Oduro, I., Ellis, W. O., \& Safo-Kantanka, O. (2007). Time of harvesting and its effect on the quality of flour from four cassava varieties. Proceedings of the 13th ISTRC Symposium, Arusha, Tanzania. p. 248-259.

Aristizabal, J., Garcia, J. A., \& Ospina, B. (2017). Refined Cassava Flour in Bread Making: A Review. Ingenieria e Investigacion, 37(1), 25-33. https://doi.org/10.15446/ing.investig.v37n1.57306

Aryeetey, E., Wireko-Manu, F. D., Asante, J. O., Laryea, D., Ellis, W. O., \& Oduro, I. (2019). Recipe Standardization of bread using Cassava-Wheat composite flour. Jounal of Culinary Science \& Technology, 17(3), 232-255. https://doi.org/10.1080/15428052.2018.1429972

Ayele, H. H., Bultosa, G., Abera, T., \& Atstatkie, T. (2017). Nutritional and sensory quality of wheat bread supplemented with cassava and soybean flours. Cogent Food \& Agriculture, 3(1). https://doi.org/10.1080/23311932.2017.1331892

Bayata, A. (2019). Review of Nutritional Value of Cassava for Use as a Staple Food. Science Journal of Analytical Chemistry, 7(4), 83-91. https://doi.org/10.11648/j.sjac.20190704.12

Callejo, M. J., Bujeda, C., Rodríguez, G., \& Chaya, C. (2009). Alveoconsistograph evaluation of rheological properties of rye doughs. Spanish Journal of Agricultural Research, 7(3), 638-644. https://doi.org/10.5424/sjar/2009073-448

Cassava: Adding Value for Africa. (C:AVA). Retrieved from cava.nri.org/country/uganda

Coultate, T. P. (1999). Food: the Chemistry of Its Components (3rd ed.). The Royal Society of Chemistry, Cambridge, UK.

David, I., Danci, M., \& Chis-junior, S. (2014). The consistographic determinations of different types of amylase on the bread dough. Journal of Horticulture, Forestry and Biotechnology, 18(2), 203-207.

Defloor, L., Leijskens, R., Bokanga, M., \& Delcour, J. A. (1995). Impact of genotype, crop age and planting season on the breadmaking and gelatinisation properties of flour produced from cassava (Manihot esculenta Crantz) Flour. Journal of the Science of Food and Agriculture, 68(2), 167-174. https://doi.org/10.1002/jsfa.2740680206

Dendy, D. (1992). Perspectives in Composite and Alternative Flour Products. Natural Resources Institute, Chatham, UK. Paper presented at ICC, Paris.

Dhaka, V., Gulia, N., \& Khatkar, B. S. (2012). Application of Mixolab to Assess the Bread Making Quality of Wheat. Scientificreports, 1 (183). https://doi.org/10.4172/scientificreports.183

Dhaka, V., \& Khatkar, B. S. (2013). Mixolab thermomechanical characteristics of dough and bread making quality of Indian wheat varieties. Quality Assurance and Safety of Crops \& Foods, 5(4), 311-323. https://doi.org/10.3920/QAS2012.0166

East African Standard: DEAS 779. (2012). High quality cassava flour-Specification. East African Community.

Edwardo, M., Svanberg, U., Oliveira, J., \& Ahrne, L. (2013). Effect of Cassava Flour Characteristics on Properties of Cassava - Wheat - Maize Composite Bread Types. International Journal of Food Science. https://doi.org/10.1155/2013/305407

Eddy, N. O., Udofia, P. G., \& Eyo, D. (2007). Sensory evaluation of wheat/cassava composite bread and effect of label information on acceptance and preference. African Journal of Biotechnology, 6(20), 2415-2418. https://doi.org/10.5897/AJB2007.000-2379

Eggleston, G., Omoaka, G. P., \& Arowshegbe, A. U. (1993). Flour, starch and composite bread-making quality of various cassava clones. Journal of the Science of Food and Agriculture, 62(1), 49-59. https://doi.org/10.1002/jsfa.2740620107

Eleazu, C., Eleazu, K., Aniedu, C., Amajor, J., Ikpeama, A., \& Ebenzer, I. (2014). Effect of Partial Replacement of Wheat Flour with High Quality Cassava Flour on the Chemical Composition, Antioxidant Activity, Sensory quality, and Microbial Quality of Bread. Preventive Nutrition and Food Science, 19(2), 115-123. https://doi.org/10.3746/pnf.2014.19.2.115

Eriksson, E., Kock, K., Tortoe, C., Akonor, P. T., \& Oduro-Yeboah, C. (2014). Evaluation of the Physical and Sensory Characteristics of Bread Produced from Three Varieties of Cassava and Wheat Composite Flours. Food and Public Health, 4(5), 214-227. https://doi.org/10.5923/j.fph.20140405.02

FAOSTAT. (2011). Statistical database of food production. Retrieved from http://www.fao.org 
Giacco, C. F., \& Appolonia, B. L. (1977). Baking studies with cassava and yam rheological and baking studies of tuber-wheat flour blends. Cereal chemistry, 55(4), 423-35.

Hruskova, M., \& Famera, O. (2003). Evaluation of Wheat Flour Characteristics by the Alveo-Consistograph. Polish Journal of Food and Nutrition Sciences, 12/53(2), 25-28.

Iwe, M. O., Michael, N., Madu, N. E., Obasi, N. E., ... Onwuka, G. I. (2017). Production and Evaluation of Bread Made from High Quality Cassava Flour (HQCF) and Wheat Flour Blends. Agrotechnology, 6(3), 2-8. https://doi.org/10.4172/2168-9881.1000166

Jensen, S., Skibsted, L. H., Kidmose, U., \& Thybo, A. K. (2015). Addition of cassava flours in breadmaking: Sensory and Textural evaluation. LWT - Food Science and Technology, 60(1), 292-299. https://doi.org/10.1016/j.lwt.2014.08.037

Kent, N. L., \& Evers, A. D. (1994). Kent's Technology of Cereals (4th ed.). Pergamon, Oxford, U.K. https://doi.org/10.1533/9781855736603

Khan, M., Mahesh, C., Vineeta, P., Sharma, G. K., \& Semwal, A. D. (2019). Effect of Pumpkin Flour on the Rheological Characteristics of Wheat Flour and on Biscuit Quality. Journal of Food Processing \& Technology, 10(814). https://doi.org/10.35248/2157-7110.19.10.814

Khalil, A. H., Esam, H. M., \& Dawood, F. M. (2000). Influence of Malt on Rheological and Baking Properties of Wheat-cassava Composite Flours. Lwt - Food Science and Technology, 33(3), 159-164. https://doi.org/10.1006/fstl.1999.0629

Kleih, U., Phillips, D., Jagwe, J., \& Kirya, M. (2012). Cassava market and value chain analysis. Uganda Case Study. C:AVA Final Report. Natural Resources Institute, UK and Africa Innovations Institute, Uganda.

Koksel, H., Kahraman, K., Sanal, T., Ozay, D. S., \& Dubat, A. (2009). Potential utilization of Mixolab for Quality Evaluation of Bread Wheat Genotypes. Cereal Chemistry, 86(5), 522-526. https://doi.org/10.1094/CCHEM-86-5-0522

Kumar, K. A., Sharma, G. K., Khan, M. A., Govindaraj, T., \& Semwal, A. D. (2015). Development of multigrain premixes-its effect on rheological, textural and micro-structural characteristics of dough and quality of biscuits. Journal of Food Science and Technology, 52(12), 7759-7770. https://doi.org/10.1007/s13197-015-1950-9

Lawless, H. T., \& Heymann, H. (1999). Sensory Evaluation of Food - Principles and Practice. Chapman \& Aspen Publ.. Inc.: Gaithersburg, MD, USA. https://doi.org/10.1007/978-1-4615-7843-7_3

Linus-Chibueze, M. O. I., Ngadi, Md. A., \& Obasi, N. E. (2017). Bread form Cassava-Wheat Composite Flours: Effect of Cassava Varieties, Flour Composite and Improvers on the Physical and Sensory Properties of Bread Loaves. Imperial Journal of Interdisciplinary Research, 3.

Lu, H., Guo, L., Zhang, L., Xie, C., Li, W., Gu, B., \& Li, K. (2019). Study on quality characteristics of cassava flour and cassava flour short biscuits. Food Science \& Nutrition, 2020(8), 521-533. https://doi.org/10.1002/fsn3.1334

Macedo, C., Nunes, M. C., Sousa, I., \& Raymundo, A. (2020). Rheology Methods as a Tool to study the Impact of Whey Powder on the Dough and Breadmaking Performance of Wheat Flour. Fluids, 5(50). https://doi.org/10.3390/fluids5020050

Manano, J., Ogwok, P., \& Byarugaba-Bazirake, G. W. (2018). Chemical Composition of Major Cassava Varieties in Uganda, Targeted for Industrialisation. Journal of Food Research, 7(1). https://doi.org/10.5539/jfr.v7n1p1

Mixolab Applications Handbook, Chopin Technologies. (2012). Villeneuvve-la-Garenne, France.

Moradi, V., Khaneghah, M. A., Fallah, A., \& Akbarirad, H. (2016). Rheological properties of wheat flour with different extraction rate. International Food Research Journal, 23(3), 1056-1061.

Nwanekezi, E. C. (2013). Composite Flours for Baked Products and Possible Challenges - A Review. Nigerian Food Journal, 31(2), 8-17. https://doi.org/10.1016/S0189-7241(15)30071-0

Oladunmoye, O. O., Akinoso, R., \& Olapade, A. A. (2010). Evaluation of Some Physical-Chemical Properties of Wheat, Cassava, Maize and Cowpea Flours for Bread Making. Journal of Food Quality, 33, 693-708. https://doi.org/10.1111/j.1745-4557.2010.00351.x

Olubunmi, I. P., Akinyele, O. O., Babatunde, K. S., Olusola, O. E., Adetokunbo, O. A., \& Elemo, G. N. (2015). 
Influence of Coconut Fibre Inclusion on Rheological Properties of Composite Wheat-Cassava Flour Dough Using the Mixolab. Journal of Food and Nutrition Sciences, 3(6), 229-235.

https://doi.org/10.11648/j.jfns.20150306.15

Olubunmi, I. P., Babatunde, K. S., Bolanle, O. O., Seyioba, S. O., Latona-Tella, T., Olukayode, O. A., \& Nwankego, E. G. (2015). Quality Evaluation of Fibre- Enriched Bread. International Journal of Nutrition and Food Sciences, 4(4), 502-508. https://doi.org/10.11648/j.ijnfs.20150404.23

Owuamanam, C. I. (2007). Quality of Bread From Wheat/Cassava Flour Composite As Affected By Strength and Steeping Duration of Cassava In Citric Acid. Nature and Science, 5(4).

Oyewole, O. B., \& Odunfa, S. A. (1988). Microbiological studies on cassava fermentation for 'lafun' production. Food Microbiology, 5(3), 125-133. https://doi.org/10.1016/0740-0020(88)90010-X

Oyewole, O. B., \& Ogundele, S. L. (2001). Effect of length of fermentation on the functional characteristics of fermented cassava 'fufu. The Journal of Food Technology in Africa, 6(2), 38-40. https://doi.org/10.4314/jfta.v6i2.19283

Sabovics, M., Straumite, E., \& Galoburda, R. (2011). Assessment of the Rheological Properties of Flour using the Mixolab. FOODBALT proceedings. p. 33-38.

Sampson, G. O. (2020). Assessing Consumer Acceptability of Composite Cassava (Manihot esculenta) Bread. Food and Nutrition Sciences, 11, 990-1002. https://doi.org/10.4236/fns.2020.1111070

Sanni, L., Maziya-Dixon, B., Onabolu, A. O., Arowosafe, B. E., Okoruwa, A. E., Okechukwu, R. U., \& Geteloma, C. (2006). Cassava recipes for household food security. Ibadan, Nigeria: International Institute of Tropical Agriculture.

Siyeni, D., Mahungu, N. M., Mhone, A., Moyo, C. C., Sandifolo, V., Nthonyiwa, A., \& Jumbo, S. (2004). Use of Cassava Flour by Bakery Industries in Malawi. Proceedings 9th ISTRC-AB Symposium, Kenya. p. 793-798

Shittu, T. A., Fadeyi, F. B., \& Ladipo, M. A. (2015). Impact of cassava flour properties on the sensory quality of composite white bread. Quality Assurance and Safety of Crops \& Foods. https://doi.org/10.3920/QAS2014.0451

Shittu, T. A., Raji, A. O., \& Sanni, L. O. (2007). Bread from composite cassava-wheat flour. Effect of baking time and temperature on some physical properties of bread loaf. Food Reseach International, 40(2), 280-290. https://doi.org/10.1016/j.foodres.2006.10.012

Tajudeen, A. A. (2012). Review of Cassava and Wheat Flour Composite in Bread Making: Prospects for Industrial Application. The African Journal of Plant Science and Biotechnology, 7(1), 1-8.

Tetchi, F. A., Solomen, O. W., Kakou, A. C. K. A., \& Georges, A. N. (2012). Effect of Cassava Variety and Fermentation Time on Biochemical and Microbiological Characteristics of Raw Artisanal Starter for Attiéké Production. Innovative Romanian Food Biotechnology, 10(3), 40-47.

Uganda Bureau of Statistics (UBOS). (2020). Statistical Abstract. Retrieved from http://www.ubos.org

UNFPA. (2016). Uganda annual report. Retrieved from http://www.uganda.unfpa.org

United States Department of Agriculture (USDA). (2020). Uganda Wheat Imports by year. Retrieved from http://www.usda.govt

Xhabiri, G. Q., Durmishi, N., Idrizi, X., Ferati, I., \& Hoxha, I. (2016). Rheological Qualities of Dough from Mixture of Flour and Wheat Bran and Possible Correlation between Bra Bender and Mixolab Chopin Equipments. MOJ Food Processing \& Technology, 2(4), 00042. https://doi.org/10.15406/mojfpt.2016.02.00042

\section{Copyrights}

Copyright for this article is retained by the author(s), with first publication rights granted to the journal.

This is an open-access article distributed under the terms and conditions of the Creative Commons Attribution license (http://creativecommons.org/licenses/by/4.0/). 